\title{
Perfil dos usuários do Portal Píon de divulgação científica em Física a partír de dados do Google Analytics sobre tempo, espaço e conteúdo
}

Leonardo Sioufi Fagundes dos Santos

Professor Adjunto III da UNIFESP no Dep. de Física, campus de Diadema.

E-mail: leosioufi@gmail.com

Flamínio de Oliveira Rangel

Professor Adjunto IV da UNIFESP no Dep. de Ciências Exatas e da Terra, campus de Diadema. E-mail: flaminio.rangel@unifesp.br

Marcio de Araujo Mendes

Analista de Tecnologia da Informação da Sociedade Brasileira de Física; Desenvolvedor Web Full Stack da Jbox Solutions.

E-mail: marcio@sbfisica.org.br

Resumo: Realizamos uma pesquisa quantitativa a partir de dados da plataforma Google Analytics sobre o Portal Píon de divulgação científica da Sociedade Brasileira de Física em busca de padrões que indiquem um perfil do usuário. Estudamos as visualizações por ano, mês e dia, usuários por ano e por região do Brasil e os dez conteúdos mais visualizados no Portal no período de 01 de janeiro de 2013 a 31 de dezembro de 2017. Observamos que as visualizações aumentaram ano a ano e oscilaram aos longos dos dias e meses, apresentando quedas nos finais de semana e nos meses de janeiro, julho e dezembro; o número de usuários do Píon aumentou cinco vezes mais do que os internautas do Brasil; a distribuição geográfica dos usuários do Píon e dos domicílios com internet praticamente coincidem; os conteúdos mais acessados são os artigos de divulgação científica em Física com conteúdo de ensino básico. Os dados apontam que o perfil do usuário do Píon é do estudante ou do professor de todo o Brasil.

Palavras-chave: divulgação científica; Física; Google Analytics; distribuição; conteúdo.
Abstract: We performed a quantitative research based on data from the Google Analytics platform on the Pion Portal for scientific dissemination of the Brazilian Society of Physics in search of patterns that indicate a user profile. We studied the views by year, month and day, users by year and region of Brazil and the ten most viewed contents in the Portal from January 01, 2013 to December 31, 2017. We observed that the views increased by year and oscillated over days and months, presenting drops on weekends and in January, July and December; the number of Pion users increased five times more than the Brazilian internet users; the geographical distribution of Pion users and residences with internet practically coincide; the most accessed contents were articles of scientific dissemination in Physics with content of basic education. The data indicate that the profile of the Pion user is of the student or the professor from all over Brazil.

Keywords: scientific dissemination; Physics; Google Analytics; distribution; content. 
comunicação \& educação • Ano XXIII • número 2 • jul/dez 2018

1. Portal do Professor do Ministério da Educação. Disponível em: http://portaldoprofe ssor.mec.gov.br/index.html.

2. Links do Portal do Professor: http://portaldoprofes sor.mec.gov.br/links.html.

3. CASCAIS, Maria da Graça; TERÁN, Augusto Fachín. Educação formal, informal e não formal na educação em ciências. Ciência em Tela Rio de Janeiro, v. 7, n. 2, pp. 1-10, dez. 2014. Semestral. Disponível em: <http:// www.cienciaemtela.nutes. ufrj.br/artigos/0702enf. $\mathrm{pdf}>$. Acesso em: $17 \mathrm{set}$. 2018

4. BRASIL, Ministério da Educação. Legislação de Educação à Distância. Disponível em: http://portal.mec.gov.br/expansao -da-rede-federal/193-se cretarias-112877938/seed-educacao-a-distan cia-96734370/12778-legis lacao-de-educacao-a-dis tancia.

5. FERREIRA, Luciana Nobre de Abreu; QUEIROZ, Salete Linhares. Textos de divulgação científica no ensino de ciências: uma revisão. Alexandria, Florianópolis, v. 5, n. 1, pp. 3-31, jun. 2012 Disponível em: <https:// periodicos.ufsc.br/index. php/alexandria/article/ view/37695>. Acesso em: 17 set. 2018

6. ENCONTRO INTERNACIONAL DE PRODUÇÃO CIENTIFICA, n. 8, 2013, Maringá. Anais Eletrônico Maringá: Cesumar, 2013. 9p. Disponível em: <http:// www.cesumar.br/prppge/ pesquisa/epcc2013/oit mostra/Denise_Fontanella. $\mathrm{pdf}>$. Acesso em: $17 \mathrm{set}$. 2018.

7.STRACK, Ricardo; LOGUÉRCIO, Rochele; PINO, José Claudio del. Percepções de professores de ensino superior sobre a literatura de divulgação científica. Ciência \& Educação, Bauru, [s. I.], v. 15 n. 2, pp. 425-442, 2009. FapUNIFESP (SciELO). Disponível em: <https:// dx.doi.org/10.1590/s15 16-73132009000200012>. Acesso em: 17 set. 2018.

\section{INTRODUÇÃO}

A internet facilitou o acesso ao conhecimento científico através de um gigantesco acervo de recursos didáticos e materiais multimídia, desde a divulgação científica sobre conceitos rudimentares até aos últimos avanços da ciência. Por exemplo, o Ministério da Educação (MEC) fornece gratuitamente no Portal do Professor 13.898 recursos multimídias educacionais ${ }^{1}$ e apresenta hiperlinks para 126 portais sobre o tema ${ }^{2}$. Portais e sites de divulgação científica combinam textos, materiais audiovisuais e até interatividade, caracterizando-se como "educação informal" ou "não formal"3. Escolas e universidades usam a internet para o "ensino de ciências" na Educação a distância (EaD), uma educação de caráter formal, devidamente reconhecida pela Lei de Diretrizes e Bases da Educação Nacional (LDB $)^{4}$. Mesmo em cursos presenciais, professores do ensino formal usam materiais paradidáticos de divulgação científica da internet em sala aula ${ }^{5,6,7}$.

Neste trabalho, realizaremos uma pesquisa quantitativa de uma página eletrônica de divulgação científica em Física, o Portal Píon da Sociedade Brasileira de Física $(\mathrm{SBF})^{8}$. Hospedado na página da SBF, o Píon foi criado em $2008 \mathrm{em}$ formato diferente do atual pelo jornalista Francisco Rolfsen Belda e pelo físico Nelson Studart com o apoio financeiro do CNPQ ${ }^{9}$. O nome "Píon" vem da partícula proposta e detectada pelo físico brasileiro Cesar Lattes.

No ano de 2012, uma nova equipe assumiu o Portal Píon e permanece até o presente (2018). A nova equipe não conta com apoio financeiro do CNPQ e nem de nenhuma agência de fomento. Todos os membros da equipe são físicos, docentes de universidades públicas brasileiras. O coordenador é Leonardo S. F. dos Santos (UNIFESP); o editor-executivo, Élcio Abdalla (USP); e os colaboradores, Flamínio de Oliveira Rangel (UNIFESP), Maria Tereza Thomas (UFRJ), José Sartorelli (USP) e Cláudio de Conti (UNESP). O analista de tecnologia da informação da SBF, Márcio Mendes, realizou a implantação, adequação e utilização do sistema de gerenciamento de conteúdo Joomla, deixando o Píon mais seguro, poderoso e parecido com as páginas da SBF. Além disso, Márcio Mendes instalou um contador de visitas no Portal Píon no dia 24 de agosto de 2012

A primeira versão do Píon era apresentada como uma página de "divulgação e ensino de Física”. A nova equipe restringiu a proposta do Píon, considerando as distinções entre o ensino formal e a divulgação científica ${ }^{10,11}$. Atualmente, aparece apenas como um portal de "divulgação científica em Física". O público-alvo tornou-se o estudante de qualquer faixa etária que não necessariamente domine conceitos de matemática.

A fonte dos dados desta pesquisa é a plataforma Google Analytics. Qualquer site cadastrado no Google Analytics passa a ser rastreado através de cookies ${ }^{12}$. O Portal Píon está associado ao Analytics desde o dia 24 de agosto de 2012 e desde então a plataforma fornece diversas informações sobre a navegação no site como horário, localização geográfica, conteúdo visitado, tipo do aparelho de acesso à internet (computador, celular, tablet etc.), idade e sexo do internauta etc. 
O Analytics distingue os números de visualizações e usuários ${ }^{13,14}$. O processo de contagem do número de sessões é bastante complexo $^{13}$ e este dado não será usado no presente trabalho. Cada visualização corresponde a uma página visitada ${ }^{14}$. Por exemplo, se um internauta abre uma página com uma notícia e depois outra com um artigo, o Analytics contabiliza duas visualizações. O número de usuários é contabilizado pelo aparelho (computador, telefone celular, tablet etc.) com que o internauta acessa a página. Como exemplo, se a partir de um mesmo computador são realizadas duas visualizações, o Analytics contará apenas um único usuário ${ }^{14}$.

O que o Analytics denomina visualização o contador do Portal Píon chama de visita. Há uma diferença entre o número de visualizações informado pelo Analytics e o contador do próprio Portal. Desde o 24 de agosto de 2012 até 20 de maio de 2018, o Google Analytics contabilizou 622.742 visualizações, enquanto o contador da página registrou 1.000 .063 visitas. Isso significa que o Analytics contou $62 \%$ das visualizações. A explicação para esta diferença está no método de contagem. De acordo com o site Código Fonte ${ }^{13}$, a coleta de dados é perdida quando uma pesquisa do Google usa o "https" no lugar de "http". Além disso, o mesmo site e o blog "Internet Innovation"14 apontam que problemas na habilitação dos cookies e na linguagem JavaScript impedem todo o mecanismo de contagem. O site Search Engine Land ${ }^{15}$, citado pelo Código Fonte, indica uma perda de contagem de aproximadamente 39\% devido aos problemas já mencionados, o que equivale a uma apuração de $61 \%$ das visualizações, praticamente a mesma diferença relativa entre os dados do Analytics e do contador da página.

Os problemas de contagem de visualizações do Analytics não dependem do instante em que a internet é acessada, nem da localização geográfica, nem do sexo, nem da idade etc. Então, as visualizações não contadas são aleatórias, não afetando as distribuições estatísticas de acesso por tempo, posição geográfica, sexo, idade e nem de nenhuma outra variável. Em suma, as visualizações não registradas não comprometem os dados estatísticos do Analytics.

O objetivo principal desta pesquisa é buscar padrões nos acessos ao Portal Píon que indiquem algum perfil do público do Píon. Por exemplo, um aumento no número de acessos nos finais de semana evidencia que o Portal serve como entretenimento. Já um site mais visitado nos dias de semana aponta o uso do Píon para fins educacionais ou profissionais. Outro exemplo de padrão é a concentração desproporcional de acessos numa determinada região do Brasil. Se essa concentração ocorre, o site está com a linguagem específica de uma determinada área geográfica. Outro padrão é a visita a conteúdos. Os conteúdos mais acessados mostram o que público do Portal está buscando.

Os dados explorados neste trabalho serão: distribuição de visualizações por tempo (ano, mês e dia); distribuição de usuários por ano; distribuição de usuários por região brasileira; e distribuição de visualizações por conteúdo. A inspiração destas questões vem da própria Física, uma vez que a dinâmica de uma partícula que depende da sua massa (conteúdo) e da posição (espaço) nos sucessivos instantes de tempo.
8. SANTOS, Leonardo Sioufi Fagundes dos et al (org.). Portal Píon. Disponivel em: <http://www. sbfisica.org.br/v1/novo pion/>. Acesso em: 17 set. 2018.

9. ESCANHOELA, Felipe Moron; STUDART, Nelson. O que os professores pensam sobre o Píon, o Portal SBF de Ensino e Divulgação da Física. Caderno Brasileiro de Ensino de Física, [s. I.], v. 29, n. 8, pp. 327-345, 8 out. 2012. Universidade Federal de Santa Catarina (UFSC). Disponível em: <http:// dx.doi.org/10.5007/ 2175-7941.2012v29nes p1p390>. Acesso em: 17 set. 2018.

10. ENCONTRO NACIONAL DE PESQUISA EM EDUCAÇÃO EM CIÊNCIAS, 2003.

11. VIEIRA, Cássio Leite. Pequeno Manual de Divulgação Científica: dicas para cientistas e divulgadores da Ciência. Rio de Janeiro: Instituto Ciência Hoje, 2006.

12. GOOGLE Analytics: Cookies e identificação do usuário. Disponível em: $<$ https://developers.goo gle.com/analytics/devgui des/collection/analyticsjs/ cookies-user-id?hl=pt-br>. Acesso em: 17 set. 2018.

13.SILVA, Carlos L. A. da. 16 falhas do Google Analytics e o que você pode fazer a respeito. Disponível em: <https://www. codigofonte.com.br/ar tigos/16-falhas-do-goo gle-analytics-e-o-que-vo ce-pode-fazer-a-respeito>. Acesso em: 17 set. 2018.

14. INTERNET INNOVATION: Seria bom se fosse verdade, mas é um mito. O Google Analytics nem sempre consegue contabilizar 100\% dos acessos em seu site e vamos explicar o porquê. Disponível em: <https://www.internetin novation.com.br/blog/ mito-ou-verdade-o-goo gle-analytics-contabili za-todas-as-visitas-de -um-site/>. Acesso em: 17 set. 2018. 
Consideramos que o número de visualizações reflete o interesse do internauta pelo Píon melhor do que a contagem de usuários. Esta é a razão para estudar o número de visualizações por tempo e por conteúdo. No entanto, os dados sobre usuários também são muito importantes porque podem ser comparados com as pesquisas acerca da distribuição dos internautas no Brasil e a sua expansão ao longo dos anos. Devido a isso, pesquisamos os dados a respeito da distribuição de usuários por ano e por região brasileira.

Apesar da importância, não serão usados dados relativos à idade e ao sexo dos internautas, porque o internauta que visita o Píon não é necessariamente o proprietário do aparelho a partir de onde o Analytics coleta os seus dados. Além disso, informações sobre menores de 18 anos são omitidas pelo Analytics ${ }^{16}$, o que camufla dados valiosos acerca do internauta do ensino básico. Outros dados do Analytics também serão descartados, como o número de sessões, página por sessão, tempo por sessão, taxa de rejeição, conclusões de meta, novos usuários, taxa de conversão de meta etc. Estes dados são importantes, mas os números de visualizações e usuários são suficientes para um estudo do perfil do internauta do Píon.

Os dados coletados são relativos, como já mencionado, ao período de 01 de janeiro de 2013 até 31 de dezembro de 2017. Escolhemos este intervalo por conter cinco anos completos, o que permite a avaliação da evolução do número de visualizações e usuários por ano.

Justificamos esta pesquisa pela necessidade de planejamento do Portal Píon e de páginas eletrônicas de divulgação científica, em geral. Uma divulgação científica voltada a um público muito restrito não tem sentido em um país que carece dos conceitos científicos mais elementares.

$\mathrm{O}$ artigo segue o roteiro a seguir: na próxima seção apresentamos os dados da distribuição de visualizações anuais, mensais e diárias; a distribuição de usuários por ano, o número de usuários nas cinco regiões do Brasil e uma lista dos dez conteúdos mais visualizados no Portal Píon são mostrados respectivamente na terceira, quarta e quinta seções; o trabalho termina com as seções da discussão dos dados e da conclusão.

15. SCHWARTZ, Barry. Search Engine Land: Study: $39 \%$ Of Google Search Referrers Now "Not Provided". Disponível em: <http:// searchengineland.com/ google-search-referre rs-not-provided-139416>. Acesso em: 17 set. 2018.

16. GOOGLE Analytics: sobre a segmentação demográfica. Disponível em: <https://support.goo gle.com/adwords/ans wer $/ 2580383$ ?hl=pt-BR\& $\mathrm{utm} \_\mathrm{id}=\mathrm{ad}>$. Acesso em: 17 setembro 2018

\section{DISTRIBUIÇÃO DE VISUALIZAÇÕES POR TEMPO}

O Analytics exibe o número de visualizações por hora, dia, semana e mês ao longo de um período qualquer, mas não há a mesma opção para ano. No entanto, o Analytics contabiliza o número total de visualizações em um período dado. Desta forma, também é possível calcular o número de visualizações por ano. O Analytics exibe gráficos e permite gerar os dados em arquivos "pdf" ou "xlsx", em que o último tipo pode ser lido pelo Excel.

A Figura 1 exibe o número de visualizações por ano no período estudado. O número de visualizações por mês no período está na Figura 2. 
O gráfico da Figura 2 indica uma oscilação no número de visualizações ao longo do ano. Para confirmar se há uma relação entre o mês do ano e o número de visualizações é necessária uma comparação entre os meses em anos distintos.

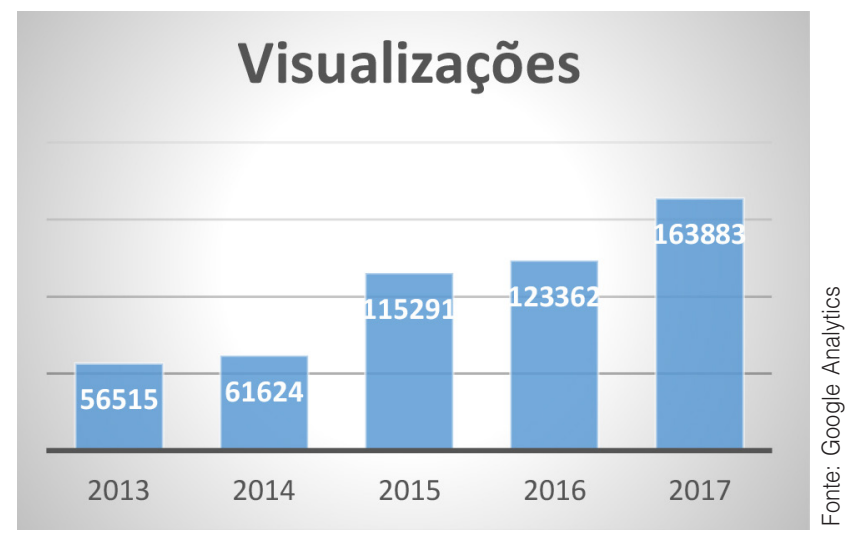

Figura 1: Número de visualizações por ano entre 01 de janeiro de 2013 e 31 de dezembro de 2017

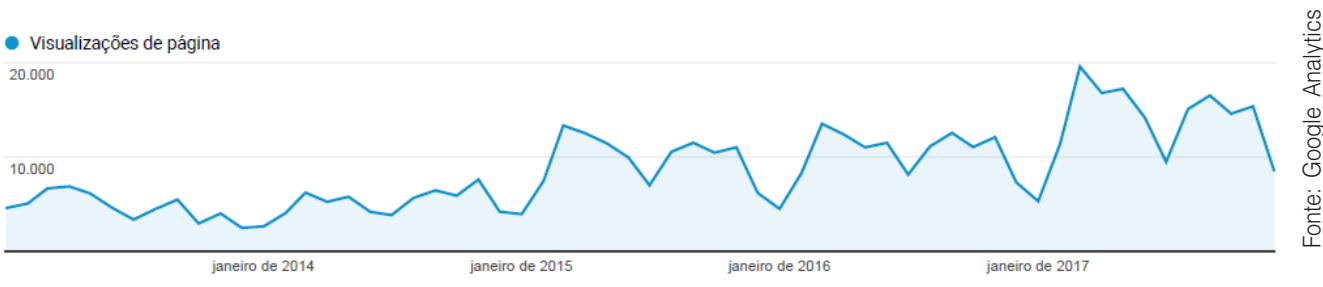

Figura 2: Número de sessões por mês entre 01 de janeiro de 2013 e 31 de dezembro de 2017

Com os dados da Figura 1 exportadas para um arquivo xlsx, aberto no programa Excel, é possível somar as visualizações de cada mês em particular ao longo dos anos. Por exemplo, os meses de janeiro dos anos de 2013, 2014, 2015, 2016 e 2017 correspondem respectivamente aos números de visualizações $4.564,2.629,3.926,4.488$ e 5.295. Portanto, os meses de janeiro resultam em 20.092 visualizações. Com procedimento análogo, chega-se ao número de visualizações de cada um dos outros onze meses. A divisão do número de visualizações de um mesmo mês ao longo dos cinco anos diferentes dividido pelo número total de visualizações no período estudado, 520.675, resultam em uma fração. Por exemplo, os meses de janeiro abarcaram 20.092 visualizações de 520.675, o que representa uma fração de 20.092/520.6750,0401=4,01\%. A Figura 3 exibe um gráfico gerado pelo Excel com as frações de visualizações de cada mês ao longo dos cinco anos em forma de porcentagem.

O número de visualizações diárias no período está na Figura 4.

O gráfico da Figura 4 mostra uma oscilação na escala de dias independente da variação ao longo dos meses. Analogamente ao que foi feito para 
a distribuição de visualizações por mês, é necessário somar as visualizações de cada um dos 7 dias da semana no período estudado. A Figura 5 mostra a porcentagem de visualizações por dia da semana no intervalo abarcado.

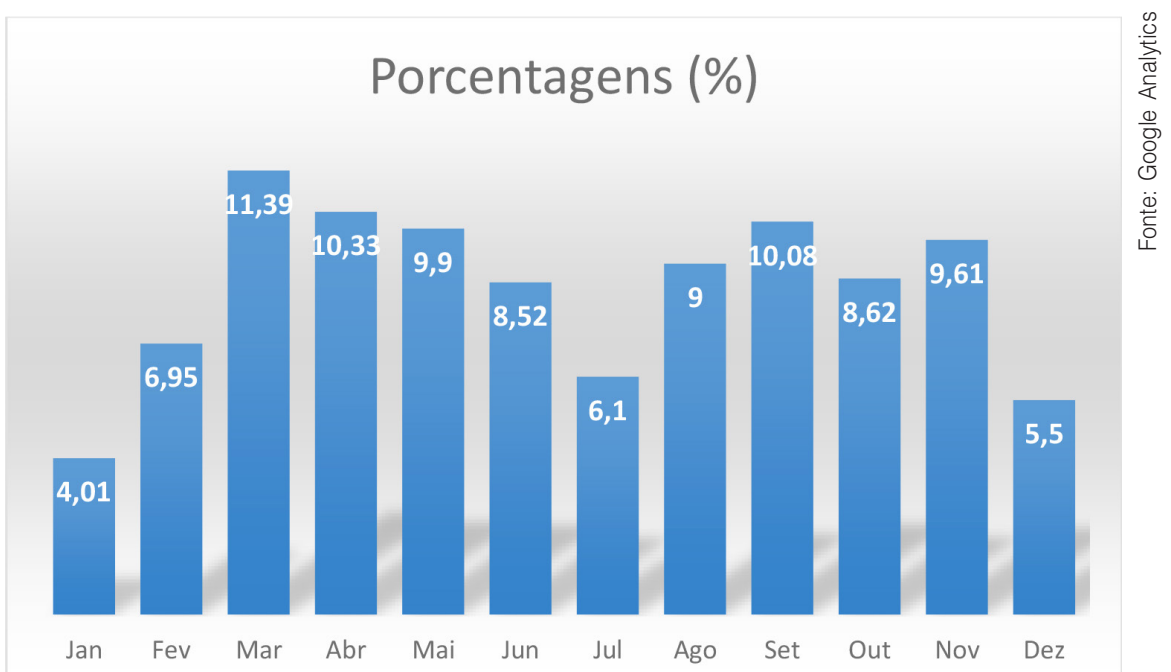

Figura 3: Número de visualizações em cada mês entre 01/01/2013 e $31 / 12 / 2017$

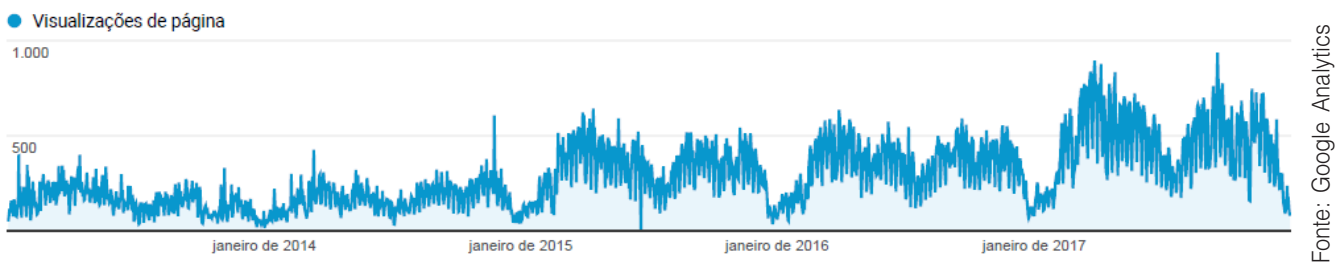

Figura 4: Número de visualizações diárias entre 01 de janeiro de 2013 e 31 de dezembro de 2017

A única ressalva que se poderia fazer sobre a Figura 4 é a assimetria de dias da semana no intervalo citado. Há 261 terças, quartas, quintas, sextas, sábados e domingos, mas o número de segundas é de 260. Esta objeção pode ser descartada porque uma diferença de 1 dia em conjuntos de 5 anos é de aproximadamente $0,055 \%$. 

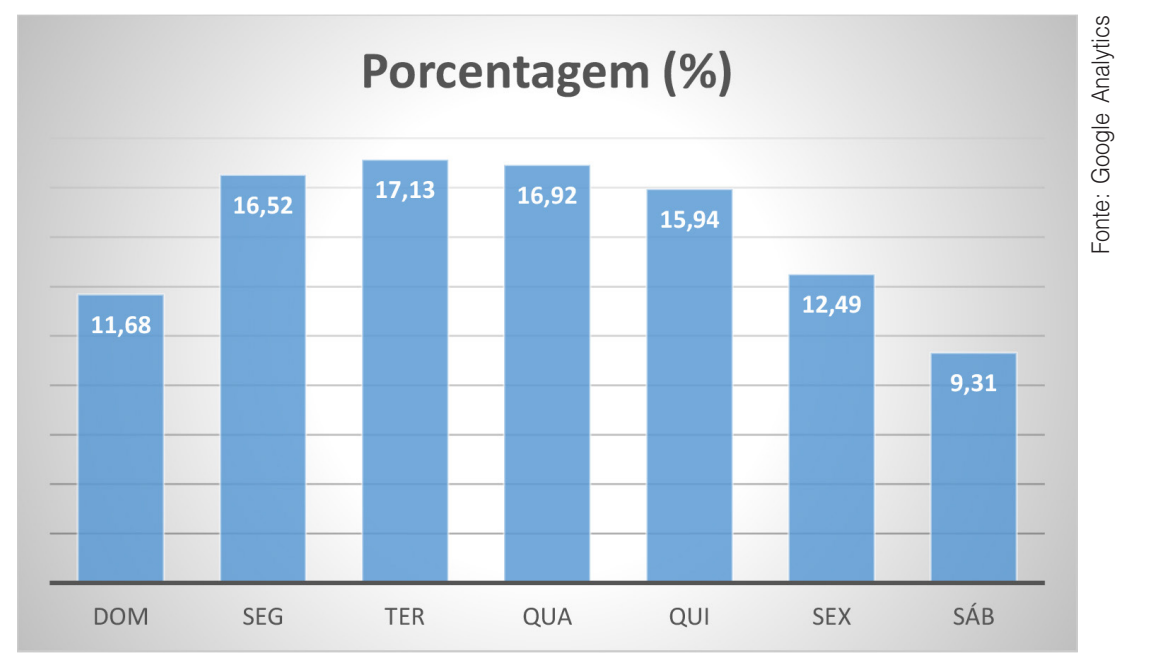

Figura 5: Número de visualizações em cada dia da semana entre 01 de janeiro de 2013 e 31 de dezembro de 2017

\section{DISTRIBUIÇÃO DE USUÁRIOS POR ANO}

A obtenção dos dados do número de usuários por ano é análoga a do número de visualizações anuais. A Figura 6 mostra o número anual de usuários no período de 2013 a 2017.

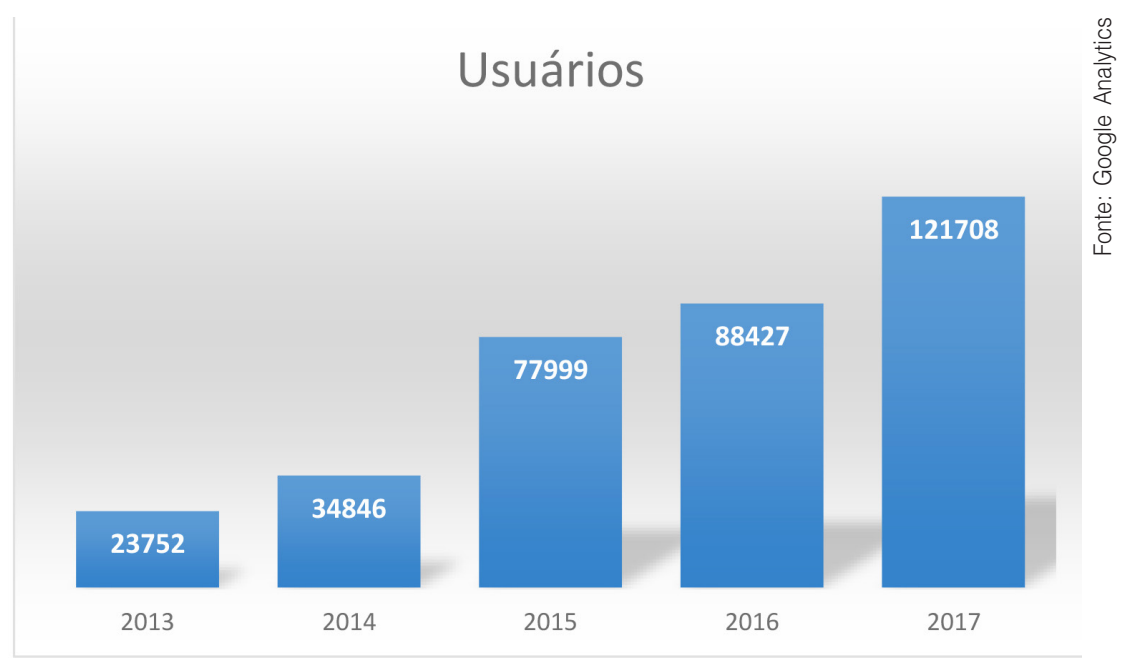

Figura 6: Número de usuários por ano entre 01 de janeiro de 2013 a 31 de dezembro de 2017

\section{DISTRIBUIÇÃO DE USUÁRIOS POR REGIÃO DO BRASIL}

Os dados da distribuição geográfica dos usuários fornecidos pelo Analytics são muito ricos, identificando o número de usuários por cidade, estado e país. 
De acordo com o Analytics, no intervalo estudado, o Píon teve 340.448 usuários. Os usuários brasileiros constituem 94,68\% do total mundial. Há um grupo de $0,58 \%$ dos usuários que o Analytics não consegue rastrear a origem, aparecendo como "not set".

Embora o número de usuários por cidade, estado e país seja detalhado no Analytics, apenas a distribuição pelas cinco regiões do Brasil será exibida neste trabalho. O número de usuários por região dividido pelo total de usuários do Brasil é a fração de usuários em cada região (ver Figura 7). Uma fração insignificante dos usuários brasileiros, 0,26\%, não foi localizada pelo Analytics em nenhum estado em particular, recebendo a mesma classificação já mencionada, "not set". Este grupo foi excluído desta análise.

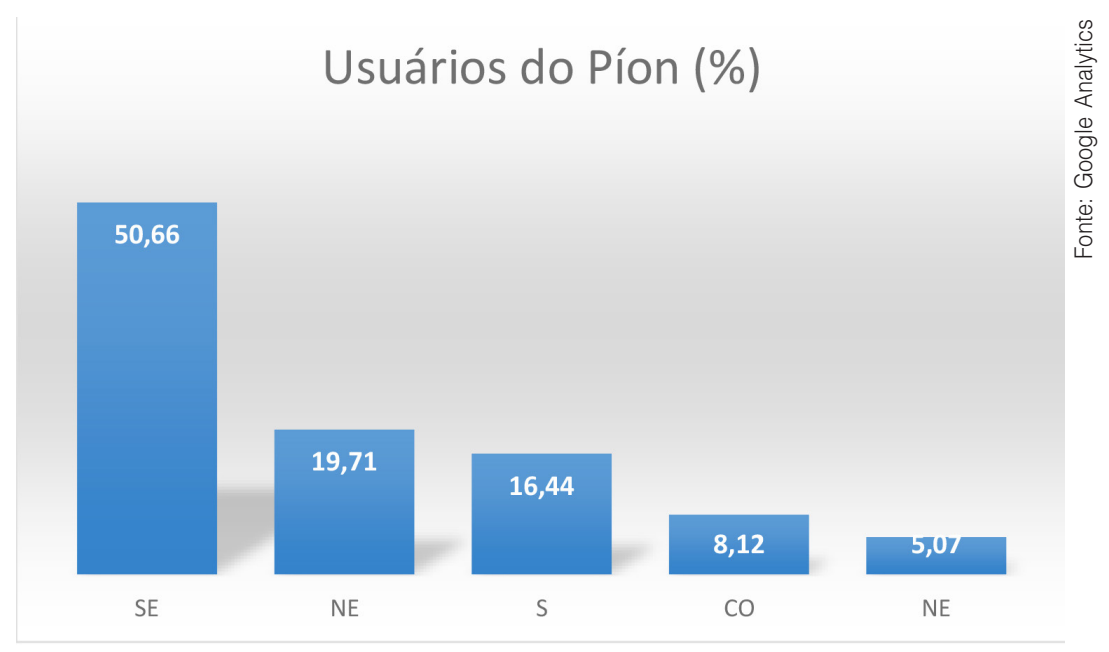

Figura 7: Porcentagem do número de usuários por região do Brasil entre 01 de janeiro de 2013 e 31 de dezembro de 2017

17. http://www.sbfisica. org.br/v1/novopion/ index.php/publicacoes/ artigos/479-3-6.

18. http://www.sbfisica. org.br/v1/novopion/index. php/publicacoes/artigos/ $479-3-6+\& c d=1 \& h l=p t-B R$ $\& c t=c \mid n k \& g l=b r$.

19. http://www.sbfisica. org.br/v1/novopion/ index.php/publicacoes/ artigos/479-3-6\&gws _rd=cr\&ei=rvcnVr-wDcK xwATFtoLADQ.

\author{
de janeiro de 2013 e 31 de dezembro de 2017
}

\section{LISTA DOS DEZ CONTEÚDOS MAIS VISUALIZADOS}

O Analytics discrimina o número de visualizações que cada página em particular do Píon recebeu em um determinado período. Por exemplo, ele pode contar as visualizações de cada artigo, de cada notícia, de cada material didático etc. Além disso, para cada página, informa a porcentagem de visualizações, o tempo médio de cada visualização, o número de sessões com a respectiva porcentagem etc.

O Analytics distingue as visualizações feitas por endereços diferentes. Por exemplo, o Analytics conta separadamente as visualizações do artigo do Píon "3,6" diretamente no site ${ }^{17}$ (154.926 visualizações), através de uma busca ${ }^{18}$ (dez visualizações), por um hiperlink ${ }^{19}$ (duas visualizações). Ao todo, o artigo "3,6" foi visualizado por 54 endereços diferentes.

Selecionamos os dez conteúdos mais visualizados do Píon no período sob análise com os respectivos números de visualizações, porcentagens e tempo de 
visualização, tomando o cuidado de considerar cada página através de todos os endereços possíveis (ver Tabela 1). Ainda na Tabela 1 acrescentamos uma coluna com o número de visualizações por dia, uma informação que não é dada diretamente pelo Analytics.

Tabela 1: Número de visualizações por conteúdo entre 24 de agosto de 2012 e 23 de agosto de 2017

\begin{tabular}{|c|c|c|c|c|}
\hline Página & $\begin{array}{l}\text { Número de } \\
\text { Visualizações } \\
\text { em ordem } \\
\text { decrescente }\end{array}$ & $\begin{array}{l}\text { Porcentagem de } \\
\text { visualizações em } \\
\text { relação ao total }\end{array}$ & $\begin{array}{l}\text { Tempo } \\
\text { médio na } \\
\text { página }\end{array}$ & $\begin{array}{l}\text { Número de } \\
\text { visualizações } \\
\text { por dia }\end{array}$ \\
\hline $\begin{array}{l}\text { Artigo de divulgação } \\
\text { científica: " } 3,6 \text { ". }\end{array}$ & 155.009 & 29,77 & $6 \min 44 s$ & 102,72 \\
\hline Simulações e animações. & 56.467 & 10,84 & $2 \min 26 s$ & 30,92 \\
\hline Portal Píon (homepage). & 34.896 & 6,71 & $1 \mathrm{~min} 28 \mathrm{~s}$ & 19,11 \\
\hline $\begin{array}{l}\text { Artigo de divulgação } \\
\text { científica: "60+60=63?". }\end{array}$ & 21.556 & 4,14 & $6 \min 58 s$ & 14,19 \\
\hline $\begin{array}{l}\text { Artigo de divulgação } \\
\text { científica: "Galileu, o } \\
\text { mensageiro das estrelas". }\end{array}$ & 18.451 & 3,54 & $5 \min 48 s$ & 10,26 \\
\hline $\begin{array}{l}\text { Artigo de divulgação } \\
\text { científica: "Temperatura } \\
\text { do corpo durante as } \\
\text { atividades físicas". }\end{array}$ & 17.677 & 3,40 & $5 \min 55 s$ & 9,68 \\
\hline $\begin{array}{l}\text { Exercício resolvido de } \\
\text { Cinemática sobre cálculo } \\
\text { de velocidade média }\end{array}$ & 12.984 & 2,49 & $4 \mathrm{~min} 30 \mathrm{~s}$ & 13,78 \\
\hline $\begin{array}{l}\text { Exercício resolvido de } \\
\text { Cinemática sobre cálculo } \\
\text { de distância percorrida }\end{array}$ & 10.087 & 1,94 & $4 \min 40 s$ & 11,57 \\
\hline $\begin{array}{l}\text { Artigo de divulgação } \\
\text { científica: Para entender } \\
\text { a irradiação e a } \\
\text { contaminação radioativa }\end{array}$ & 8.337 & 1,60 & $6 \mathrm{~min} 37 \mathrm{~s}$ & 4,57 \\
\hline $\begin{array}{l}\text { Biografia: Mario } \\
\text { Schenberg }\end{array}$ & 8.107 & 1,56 & $6 \min 14 s$ & 4,44 \\
\hline
\end{tabular}

O tempo médio de visualização é especialmente importante para os artigos. Se o tempo médio de permanência não é suficiente para a leitura do artigo, o internauta não leu o texto inteiro.

O número de visualizações por dia de uma determinada página pode corrigir uma distorção proveniente do dia em que um conteúdo foi disponibilizado. Por exemplo, um conteúdo postado há 100 dias com 200 visualizações teve duas visualizações por dia. Já outro conteúdo colocado no site há 300 dias com 450 visualização obteve 1,5 visualização por dia. Isso demonstraria um grau de interesse maior por um conteúdo que teve um número menor de visualizações. 
comunicação \& educação • Ano XXIII • número 2 • jul/dez 2018

20. AVELLAR E DUARTE, Internet no Brasil, 2012. Disponível em: <http://www. avellareduarte.com.br/ fases-projetos/conceitua cao/demandas-do-publico/ pesquisas-de-usuarios-ati vidades-2/internet-no-bra sil-2015-dados-e-fontes/ internet-no-brasil-2012-da dos-e-fontes/>. Acesso em: 17 setembro 2018.

21. WEARE SOCIAL: Digital in 2017: Global Interview, 2017, p. 28. Disponível em: <https://wearesocial. com/special-reports/digi tal-in-2017-global-o verview>. Acesso em: 17 set. 2018.

22. BRASIL. População brasileira passa de 207,7 milhões em 2017. Disponível em: <http://www.brasil. gov.br/cidadania-e-justi ca/2017/08/populacao-bra sileira-passa-de-207-7-mi Ihoes-em-2017>. Acesso em: 17 set. 2018.

23. CETIC, Pesquisa sobre usos de tecnologia de informação e comunicação em domicílios brasileiros-TIC Domicílios, 2015. Disponível em: <http:// cetic.br/media/docs/publi cacoes/2/TIC_Dom_2015_ LIVRO_ELETRONICO.pdf>. Acesso em: 17 set. 2018.

24. BRASIL, Secretaria Especial de Comunicação Social. Pesquisa Brasileira de Mídia-2016, Relatório Final, 2017. Disponível em: <http://www.secom.gov. br/atuacao/pesquisa/lista -de-pesquisas-quantitati vas-e-qualitativas-de-con tratos-atuais/pesquisa-bra sileira-de-midia-pbm-2016. pdf/view>. Acesso em: 17 set. 2018.

\section{DISCUSSÃO}

A Figura 1 mostrou que o número de visualizações anuais aumentou ano após ano no período de 2013 a 2017, subindo de 56.515 em 2013 para 163.883 em 2017, o que equivale a $190 \%$ de aumento. No mesmo período, o número de usuários apresentado na Figura 6 teve um aumento mais significativo, começando com 23.752 e terminando com 121.708, uma multiplicação de 5,12 em 5 anos, uma expansão de $412 \%$. Paralelamente ao aumento de visualizações do Píon, o número de internautas no Brasil subiu de 80,9 milhões em $2012^{20}$ para 137,1 milhões em 2017 (66\% da população brasileira ${ }^{21}$ de 207,7 milhões ${ }^{22}$ ), o que dá um acréscimo de quase $69 \%$. O crescimento do Píon em termos percentuais, $412 \%$, é quase de 6 vezes a expansão do número de internautas brasileiros, $69 \%$.

$\mathrm{Na}$ escala mensal, de acordo com as figuras 2 e 3, o número de visualizações apresenta um caráter cíclico. Janeiro, julho e dezembro abrangem respectivamente $4,01 \%, 6,1 \%$ e $5,5 \%$ das visualizações, as três menores porcentagens dos meses do ano. Em suma, três meses do ano (25\% do ano) recebem juntos apenas $15,7 \%$ das visualizações.

$\mathrm{Na}$ escala diária, a Figura 4 indica mudanças bruscas, enquanto a Figura 5 confirma uma oscilação semanal. Os dois dias com menores frações de visualizações são sábado e domingo, respectivamente com 9,31\% e 11,68\%. Sábado e domingo constituem juntos 28,57\% do tempo semanal, mas abrangem 20,99\% das visualizações.

Não encontramos dados para uma comparação entre a oscilação anual de visualizações do Píon e o movimento geral da internet. No entanto, pudemos fazer essa comparação indireta em relação à oscilação semanal correspondente. De acordo com o Relatório Final da Pesquisa Brasileira de Mídias realizada pelo IBOPE a serviço do Governo Federal em 2016, na página $27^{23}$, o tempo médio gasto pelos brasileiros com internet por dia nos dias de semana (de segunda-feira a sexta-feira) e nos finais de semana é de respectivamente 283,8 minutos e 217,7 minutos. De acordo com estes dados, a fração de tempo na internet no fim de semana de um internauta típico é de $26,79 \%$. Em contraste com o típico internauta brasileiro, o usuário do Píon despende apenas 20,99\% do mesmo período.

A distribuição geográfica dos usuários do Píon pode ser comparada com os dados da "Pesquisa sobre usos de tecnologia de informação e comunicação em domicílios brasileiros - TIC Domicílios 2015”, realizada pelo Centro Regional de Estudos para o Desenvolvimento da Sociedade da Informação (CETIC) sob os auspícios da $\mathrm{UNESCO}^{24}$ sobre o número de domicílios com internet por região. Esta pesquisa $^{23}$ não informa diretamente a porcentagem dos domicílios com internet por região, mas tal informação pode ser obtida a partir dos dados da Tabela 1 da página 133 da referência citada ${ }^{23}$. A comparação das porcentagens de residências com acesso à rede no Brasil e dos usuários em cada região praticamente coincidem (ver Figura 8). A diferença de porcentagem de distribuição dos usuários do Píon e dos internautas brasileiros é inferior a 1\% em cada uma das cinco regiões do Brasil. 
Os dados relativos ao conteúdo revelam que as dez páginas mais postadas totalizam 65,99\% das visualizações (ver Tabela 1). Assim, essa amostra particular do Portal Píon é suficiente na compreensão dos conteúdos buscados pelos internautas. As informações dos próximos sete parágrafos estão na Tabela 1.

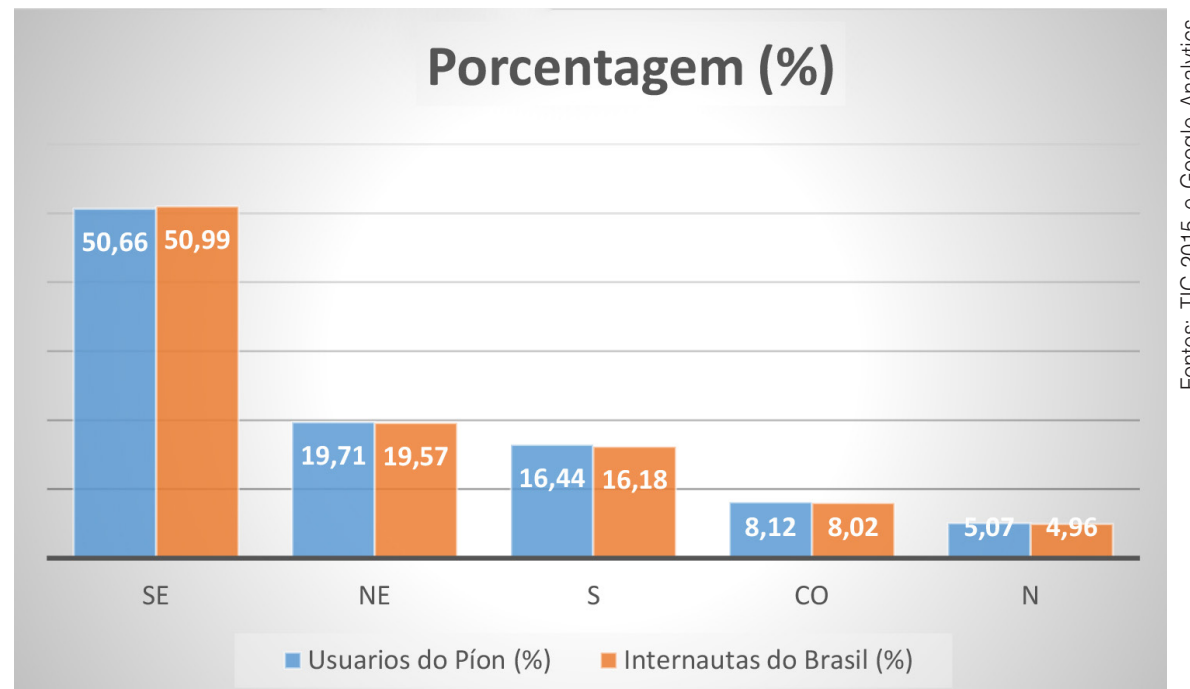

Figura 8: Porcentagens de usuários do Portal Píon entre 01 de janeiro de 2013 e 31 de dezembro de 2017 nas cinco regiões do Brasil (azul) comparada com domicílios com internet (laranja)

O conteúdo mais visualizado no Píon, tanto em número de acessos totais como em visualizações diárias, foi o artigo “3,6”, publicado em 14 de novembro de 2015. A porcentagem de visualizações é de quase 30\% do total, pouco menos do que o triplo do segundo conteúdo mais visualizado, a página "Simulações e animações". Além disso, a média diária de visualizações é quase de 103 por dia, mais do que o triplo das visualizações diárias do segundo lugar. O tempo médio de visualização do artigo 3,6 é de 6 minutos e 44 segundos, o suficiente para a leitura completa do texto. A título de curiosidade, quando o termo "3,6" foi digitado no Google no dia 21 de maio de 2018, apareceram 25.270.000.000 resultados com o artigo "3,6" em primeiro lugar.

$\mathrm{O}$ artigo em questão descreve por que o fator 3,6 converte a unidade de velocidade $\mathrm{m} / \mathrm{s}$ para $\mathrm{km} / \mathrm{h}$. O tema é pertinente a estudantes do ensino básico e a aspirantes ao ensino superior. Para entender o artigo, o leitor precisa conhecer apenas as quatro operações elementares, não sendo usada nenhuma fórmula.

O segundo conteúdo mais acessado e com maior número de visualizações diárias é a seção "Simulações e animações", com pouco mais de $10 \%$ das visualizações. Esta seção contém sites da internet com softwares gratuitos para simulações de experimentos ou de fenômenos físicos. O terceiro maior número de visualizações dos internautas é a própria homepage do Píon com 6,71\%.

O quarto, quinto, sexto e nono conteúdos mais visualizados e em cada dia particular também foram artigos de divulgação científica: "60+60=63?”, "Galileu, 
mensageiro das estrelas", "Temperatura do corpo durante atividades físicas" e "Para entender a irradiação e a contaminação radioativa". Os tempos de visualização destes artigos estão entre 5 e 7 minutos, o suficiente para uma leitura completa dos textos. Os cinco artigos de divulgação científica citados totalizam 12,68\% das visualizações do Píon, uma soma que supera o segundo conteúdo mais visualizado.

O sétimo e o oitavo lugares em visualizações são dois exercícios resolvidos de Cinemática para o ensino básico. Em número de visualizações diárias, estes conteúdos atingiram o quinto e sexto lugar em visualização diária. O décimo conteúdo mais visualizado foi a biografia do físico brasileiro Mário Schenberg com tempo de visualização de pouco mais de 6 minutos, o suficiente para uma leitura completa.

\section{CONCLUSÃO}

Concluímos que o comportamento das visualizações do Píon ao longo do tempo é diferente dos sites de internet de forma geral do Brasil. O número de visualizações em função do tempo pode ser descrito como uma sobreposição de três movimentos, uma oscilação semanal com baixas nos fins de semana, outra anual com quedas nos meses de férias escolares e um crescimento muito significativo ao longo dos anos.

Ao contrário da distribuição temporal, a difusão geográfica do Portal não é particularizada, coincidindo praticamente com a distribuição de domicílios com internet no Brasil - não ficou regionalizado. Fazer um portal de divulgação científica acessado pelos internautas de todo o Brasil de forma homogênea foi um grande desafio diante da extensão do Brasil, sua imensa população e toda a sua diversidade cultural.

Quanto ao conteúdo, o Píon se consagrou mais como um portal de artigos de divulgação científica do que um repositório de materiais audiovisuais. Entre os conteúdos mais visitados, não há visualizações para as últimas notícias científicas como a detecção do Bóson de Higgs ou das ondas gravitacionais e nem o pouso de uma sonda espacial em um cometa. O internauta do Píon busca conteúdos simples e práticos, mais uma alfabetização científica do que um jornalismo científico propriamente dito.

A partir dos dados de espaço, tempo e conteúdo, podemos elaborar algumas hipóteses acerca do perfil do internauta do Píon.

Em primeiro lugar, os resultados são compatíveis com o atual público-alvo, os estudantes. Os dias da semana e os meses que os estudantes têm aula coincidem com os maiores números de visualizações.

O público estudantil é bastante amplo e heterogêneo, mas os conteúdos

25. Disponivel em: <http:// www.sbfisica.org.br/v1/ novopion/index.php/pu blicacoes/exercicios-resol vidos/501-movimento-har monico-simples>. Acesso em: 17 set. 2018. visualizados correspondem mais ao ensino básico do que ao superior. Por exemplo, o artigo " 3,6 ” é muito útil para o estudante do ensino básico, mas é muito fácil para quem está no ensino superior. Outro exemplo de material adequado ao ensino básico do que ao superior é o artigo “60+60=63?”. Já o exercício resolvido "Movimento harmônico simples" ${ }^{25}$, direcionado ao ensino superior, 
recebeu apenas $0,06 \%$ das visualizações do Píon, um total de 336 visualizações no período de 01 de janeiro de 2013 a 31 de dezembro de 2017.

Outro público que pode estar presente no Portal Píon é o dos professores. Os mesmos conteúdos buscados por estudantes podem ser usados por professores como materiais paradidáticos. Além disso, a queda de visualizações nos finais de semana e férias escolares também é compatível com um público docente.

De acordo com os resultados deste trabalho, o perfil do usuário do Píon é de um estudante ou de professor de qualquer região do Brasil em busca de artigos de divulgação científica com conteúdo de ensino básico, em períodos associados ao trabalho e estudo. A expansão do Píon acima do aumento do número de internautas no Brasil e em meio a um crescimento explosivo na disponibilidade de materiais audiovisuais é um encorajamento à divulgação científica dirigida aos estudantes com conceitos elementares.

\section{REFERÊNCIAS BIBLIOGRÁFICAS}

AVELLAR E DUARTE. Internet no Brasil, 2012. Disponível em: <http:/ / www. avellareduarte.com.br/fases-projetos/conceituacao/demandas-do-publico/ pesquisas-de-usuarios-atividades-2/internet-no-brasil-2015-dados-e-fontes / internet-no-brasil-2012-dados-e-fontes/>. Acesso em: 17 set. 2018.

BRASIL. População brasileira passa de 207,7 milhões em 2017. Disponível em: $\quad<$ http://www.brasil.gov.br/cidadania-e-justica/2017/08/populacaobrasileira-passa-de-207-7-milhoes-em-2017>. Acesso em: 17 set. 2018.

Ministério da Educação. Legislação de Educação à Distância. Disponível em: <http://portal.mec.gov.br/expansao-da-rede-federal/193secretarias-112877938/seed-educacao-a-distancia-96734370/12778legislacao-de-educacao-a-distancia>. Acesso em: 17 set. 2018.

. Ministério da Educação. Portal do Professor. Disponível em: <http:/ / portaldoprofessor.mec.gov.br/recursos.html>. Acesso em: 17 set. 2018.

Secretaria Especial de Comunicação Social. Pesquisa Brasileira de Mídia - 2016, Relatório Final, 2017. Disponível em: <http://www.secom. gov.br/atuacao/pesquisa/lista-de-pesquisas-quantitativas-e-qualitativas-decontratos-atuais/pesquisa-brasileira-de-midia-pbm-2016.pdf/view >. Acesso em: 17 set. 2018.

CASCAIS, Maria da Graça; TERÁN, Augusto Fachín.Educação formal,informal e não formal na educação em ciências. Ciência em Tela, Rio de Janeiro, v. 7, n. 2, pp. 1-10, dez. 2014. Disponível em: <http://www.cienciaemtela.nutes. ufrj.br/artigos/0702enf.pdf>. Acesso em: 17 set. 2018.

CETIC. Pesquisa sobre usos de tecnologia de informação e comunicação em domicílios brasileiros - TIC Domicílios 2015. Disponível em: <http://cetic. 
br/media/docs/publicacoes/2/TIC_Dom_2015_LIVRO_ELETRONICO. pdf>. Acesso em: 17 set. 2018.

ENCONTRO NACIONAL DE PESQUISA EM EDUCAÇÃO EM CIÊNCIAS, n. 4. A educação não formal e a divulgação científica: o que pensa quem faz. Bauru: Abrapec, 2003. 13 p. Disponível em: <http:/ /fep.if.usp.br/ profis / arquivos/ivenpec/Arquivos/Orais/ORAL009.pdf>. Acesso em: 17 set. 2018.

ENCONTRO INTERNACIONAL DE PRODUÇÃO CIENTÍFICA, n. 8. Anais Eletrônico. Maringá: Cesumar, 2013. 9 p. Disponível em: <http://www. cesumar.br/prppge/pesquisa/epcc2013/oit_mostra/Denise_Fontanella. pdf>. Acesso em: 17 set. 2018.

ESCANHOELA, Felipe Moron; STUDART, Nelson. O que os professores pensam sobre o Pion, o Portal SBF de Ensino e Divulgação da Física. Caderno Brasileiro de Ensino de Física, [s.1.], v. 29, n. 8, pp. 327-345, 8 out. 2012. Universidade Federal de Santa Catarina (UFSC). Disponível em: <http:/ dx.doi.org/10.5007/2175-7941.2012v29nesp1p390>. Acesso em: 17 set. 2018.

FERREIRA, Luciana Nobre de Abreu; QUEIROZ, Salete Linhares. Textos de divulgação científica no ensino de ciências: uma revisão. Alexandria, Florianópolis, v. 5, n. 1, pp. 3-31, jun. 2012. Semestral. Disponível em: $<$ https://periodicos.ufsc.br/index.php/alexandria/article/view/37695>. Acesso em: 17 set. 2018.

GOOGLE ANALYTICS. Cookies e identificação do usuário. Disponível em: <https://developers.google.com/analytics/devguides/collection/ analyticsjs /cookies-user-id?hl=pt-br>. Acesso em: 17 set. 2018.

. Como uma seção da Web é definida pelo Google Analytics. Disponível em: <https://support.google.com/analytics/answer/2731565?hl=pt-BR>. Acesso em: 17 set. 2018.

A diferença entre cliques do Google AdWords e sessões, usuários, entradas, exibições de página e exibições de página únicas no Google Analytics. Disponível em: <https://support.google.com/analytics/ answer/1257084\#pageviews_vs_unique_views>. Acesso em: 17 set. 2018.

Sobre a segmentação demográfica. Disponível em: <https:// support.google.com/adwords/answer/2580383?hl=pt-BR\&utm_id=ad $>$. Acesso em: 17 set. 2018.

INTERNET INNOVATION: Seria bom se fosse verdade, mas é um mito. O Google Analytics nem sempre consegue contabilizar $100 \%$ dos acessos em seu site e vamos explicar o porquê. Disponível em: <https://www. internetinnovation.com.br/blog/mito-ou-verdade-o-google-analyticscontabiliza-todas-as-visitas-de-um-site/>. Acesso em: 17 set. 2018.

SANTOS, Leonardo Sioufi Fagundes dos et al (org.). Portal Píon. Disponível em: <http://www.sbfisica.org.br/v1/novopion/>. Acesso em: 17 set. 2018. 
SCHWARTZ, Barry. Search Engine Land: Study: 39\% Of Google Search Referrers Now "Not Provided". Disponível em: <http://searchengineland. com/google-search-referrers-not-provided-139416>. Acesso em: 17 set. 2018.

SILVA, Carlos L. A. da. 16 falhas do Google Analytics e o que você pode fazer a respeito. Disponível em: < https://www.codigofonte.com.br/artigos/16falhas-do-google-analytics-e-o-que-voce-pode-fazer-a-respeito >. Acesso em: 17 set. 2018.

STRACK, Ricardo; LOGUÉRCIO, Rochele; PINO, José Claudio del. Percepções de professores de ensino superior sobre a literatura de divulgação científica. Ciência \& Educação, Bauru, [s.1.], v. 15, n. 2, pp. 425-442, 2009. FapUNIFESP (SciELO). Disponível em: <https:/ /dx.doi.org/10.1590/s1516$73132009000200012>$. Acesso em: 17 set. 2018.

VIEIRA, Cássio Leite. Pequeno Manual de Divulgação Científica: dicas para cientistas e divulgadores da Ciência. Rio de Janeiro: Instituto Ciência Hoje, 2006.

WEARE SOCIAL. Digital in 2017: Global Interview, 2017, p. 28. Disponível em: $<$ https:/ / wearesocial.com/special-reports/digital-in-2017-global-overview>. Acesso em: 17 set. 2018. 
